\title{
Environmental and Economic Benefits of Establishing a Sustainable Transportation System Based on Internet of Things
}

Xiaotian Qi ( ivytian0818@outlook.com )

HuaXian Ministry Agriculture Rural Affairs Yi Nong Operating Center

\section{Research Article}

Keywords: Sustainable Transportation System, Internet of things, Economic and environmental benefit.

Posted Date: September 23rd, 2021

DOI: https://doi.org/10.21203/rs.3.rs-924699/v1

License: (c) (i) This work is licensed under a Creative Commons Attribution 4.0 International License.

Read Full License 


\title{
Environmental and Economic Benefits of Establishing a Sustainable Transportation System Based on Internet of Things
}

\author{
Xiaotian $Q i^{1^{*}}$ \\ HuaXian Ministry Agriculture Rural Affairs Yi Nong Operating Center, HuaXian, HeNan \\ 456400, China \\ *ivytian0818@outlook.com（password : Smart@12345）
}

\begin{abstract}
The Internet of Things (IoT) is a modern concept which has turned the conventional way of living into a high technology lifestyle. The transformations caused by loT are the smart city, smart homes, pollution control, energy savings, smart transport and the smart industries. Transportation infrastructure has a huge impact on sustainable development. Sustainable development concerns over environmental quality, social, economic vitality, and climate variation strategic planning due to increasing $\mathrm{CO} 2$ have come together to generate an increasing interest in an alternative approach. Sustainable development is very important in any pattern, particularly in the century, and it is therefore very necessary to address sustainable development. In the transport sector, sustainable development can be divided into three main areas: society, economy and environment. Consequently, in this paper, the loT driven Intelligent Transportation Framework (IoTDITF) has been proposed to establish a sustainable transportation system. Sustainable transport approaches include demand management, price policies, improvement of vehicle technology, clean fuels and integrated land use and transport scheduling. This paper attempts to analyze certain economic problems, such as realistic pricing and the development of an integrated transport network. The findings serve as a guide for policymakers, transport modelers, and planners to adopt indicators on an operating level, thereby simplifying the aggressive task of selecting an indicator.
\end{abstract}

Keywords: Sustainable Transportation System, Internet of things, Economic and environmental benefit.

\section{Significance about the research}

The Internet of Things ( IoT) is an emerging paradigm, allowing communication across the internet between electronic devices and sensors to make our lives more comfortable [1]. To address numerous concerns and problems in different industries, governmental, public and private sectors across the globe, loT utilizes intelligent tools as well as the Internet $[2,3]$. IoT slowly becomes an essential part of our lives and can be experienced 
in our existence $[4,5]$. In its essence, loT is an invention that takes together a broad range of intelligent devices, frameworks and sensors[6]. Sustainability, economic growth and sustainable transport are constantly involved [7]. Sustainability concerns are rooted in the growing awareness of the important environmental consequences of human activities that can impose economic, social and environmental costs $[8,9,10]$. Environmental pollution by the climate, the ecological consequences of generated toxins, depleted natural resources such as freshwater, and the cross-border nature of other problems in the environment all underscore the need to take a wide perspective of human impact $[11,12,13]$. The integration of human action and hence the need to integrate planning across different sectors, jurisdictions and organizations emphasize sustainable development $[14,15]$. Sustainability planning involves understanding what preventive treatment refers to safety. Sustainable development aims at an optimal balance between economic, social and environmental goals [16,17]. Figure 1 shows the internet of Things in the intelligent transportation system.

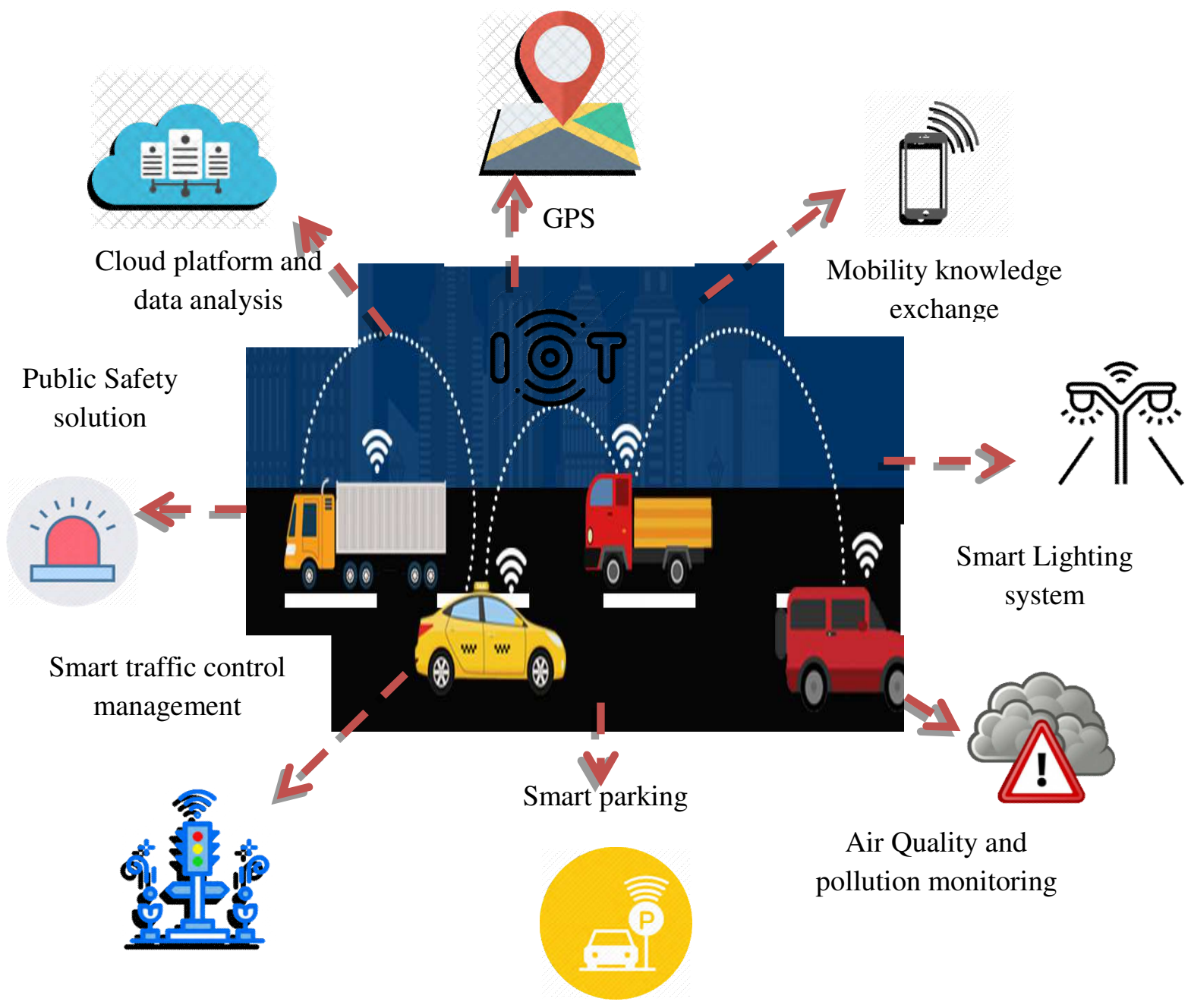




\section{Figure 1: Internet of Things in the Intelligent Transportation System}

Concerns about environmental quality, social, economic vitality, and climate variation treatment due to increasing $\mathrm{CO} 2$ has emerged there for increasing interest in the sustainable development alternative [18]. In such a way that the growth of the economy will remain and the social balance will be achieved, sustainable transport preserves the human health and environment [19]. The availability of economically and socially sustainable modes of transport (for example, bus and rail) is a key consideration in the development and success of public mobility programs [20]. In addition, the availability of alternative forms of transport, the public ability to utilize such alternative modes of transport would be another important factor [21]. Figure 2 shows the global GHG emissions by the economic sector and transportation sector.

Electricity and heat production

Manufacturing and construction

Transport

Residential

Other

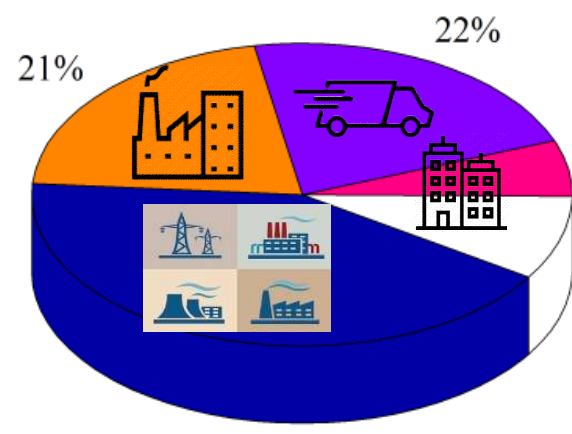

$42 \%$

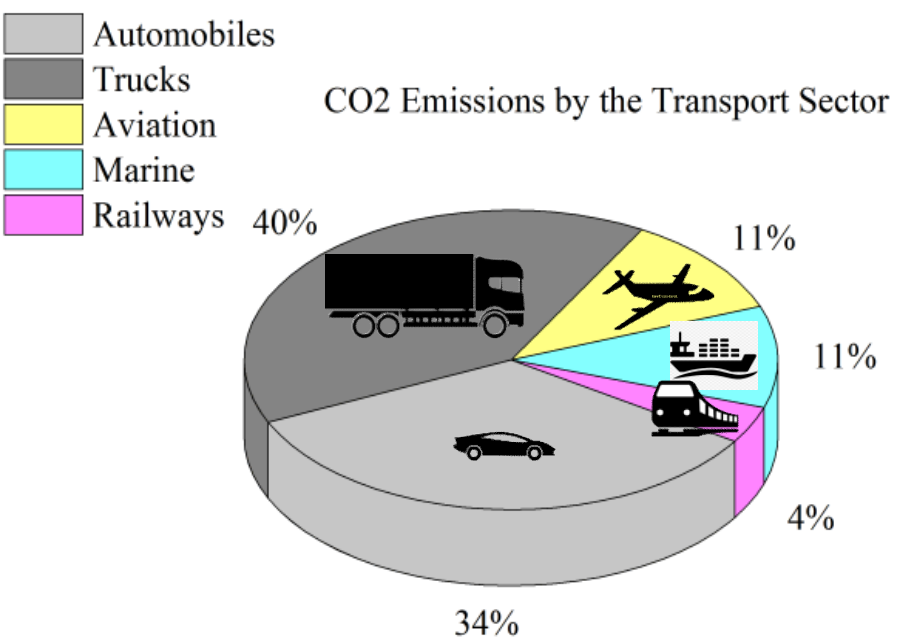

Automobile ation

$40 \%$

\section{$6 \%$}

$9 \%$

$34 \%$

Figure 2: Global GHG emissions by the economic sector and transportation sector

In this new era, the rising population of urban areas needs smart transport infrastructure. The usage of millions of devices equipped with loT technology is required to achieve smart and intelligent transport $[22,23]$. For data collection, data analysis and data management, loT plays an important and fundamental role [24]. IoT offers 
promising potential prospects to provide reliable, safe service for all users, virtually in all cases and wherever it connects all devices and facilities to different networks [25]. Throughout many cases, loT is called a new internet generation because it extends communication with humans and things [26]. The physical transport systems can be tracked in real-time, and a large number of data are produced using sensors embedded in ITS [27]. Traffic data obtained from physical devices such as GPS, inductive coils, video cameras are used widely in the management of transport, thus providing tremendous comfort for our lives [28,29]. However, the physical sensors, especially for specific applications, have certain shortcomings [30].

In this paper, the loT driven Intelligent Transportation Framework (IoTDITF) has been proposed to establish a sustainable transportation system. This research uses an integrated dynamic approach to analyze the economic and environmental effects of transport policy programs to improve sustainable mobility and determine their potential efficiency.loT leads to smart parking, autonomous vehicles, efficient control of road flow, smart routing, sequencing of traffic signs, smart road lighting, bike sharing and public transport within the context of an Intelligent transportation system (ITS). The use of loT in this area is likely to continue to increase with the proposed new requests. The IoT module in ITS displays the amount of loT devices within one domain.

The main contributions of the paper are,

- To propose the loT driven Intelligent Transportation Framework (IoTDITF) has been proposed to develop a sustainable transportation system.

- Designing the Smart parking system mathematical model for an intelligent transportation system.

- The experimental results have been executed, and the proposed approach enhances the reliability and performance of the system.

The rest of the paper discussed as follows: section 1 and section 2 discussed the introduction and previous approaches to the sustainable transportation system. In section 3, the IoT driven Intelligent Transportation Framework (IOTDITF) has been proposed to establish a sustainable transportation system. In section 4 , the numerical results have been performed. Finally, section 5 concludes the research article.

\section{Literature Survey}


Phillip Smith et al. [31] introduced the Single Valued Neutroscopic sets (SVNS) for exploring public transport sustainability. This article demonstrates a diverse decisionmaking approach to the selection of sustainable, uncertain public transport systems that contain partial or incomplete data. An SVNS is a generalization of a traditional collection, intuitionistic fuzzy set. Similar results are expected in the original study, although neutrosophic formalism opens up a wide variety of opportunities to recognize uncertainty in sustainability assessment.

Qiuping Wang et al. [32] suggested the Dynamic Game model (DGM) for traffic structure optimization in historic districts based on green transportation and sustainable development. First of all, the logit model representing the traffic sharing rate is developed via the widespread cost procedure to quantify all the variables that impact the selection of transport. A DGM is therefore developed to provide comprehensive information on the touring mode of historic areas, taking account of economic sustainability, environmental sustainability and traffic development's social sustainability.

Devendra Kumar Pathak et al. [33] introduced the sustainability performance evaluation framework (SPEF) freight transportation systems.Through resonant an extensive literature review and showing a Delphi research, they discover critical success factors ( CSFs) influencing the performing of SFT to search experts from both industry and academia. In addition, a comprehensive hierarchical structure is established to define interrelationships between these CSFs and preference CSFs.

Yuan Chen et al. [34] initialized the Data envelopment analysis and accessibility based service effectiveness model (DEA-ABSEV) for urban bus transit. The results will provide policymakers with examples of how the ABSEV allocation of bus transits can be optimized, advantages of bus transit into socially disadvanced groups improved, and public bus transit services economic growth expanded.

Aalok Kumar et al. [35] suggested Environmental and social sustainability framework (EnSoS) based on an integrated multi-criteria decision making (MCDM) approach for evaluation of the freight transportation industry. The proposed framework assesses the current level of sustainability with an index and describes the challenges for the efficient freight transport network. The Fuzzy Best-Worst Method is used to measure the 
uncertain weight of the attributes, while the fuzzy logic is used to determine the performance of the attributes.

To overcome these issues, in this paper, the loT driven Intelligent Transportation Framework (IoTDITF) has been proposed to establish a sustainable transportation system. This paper suggested the integrated transport infrastructure to attain a sustainable ITS that addresses problems such as a high level of traffic congestion, CO2 emissions, road safety. Traffic congestion decreases the transport sector efficiency. Traffic monitoring and location-driven alerts minimize the congestion in wireless networks, web-based platforms and smartphone devices such as Waze and navigation services are already focused. A specific system for transmitting alerts to the traffic location, for warning about high-risk accident areas, for communicating precautions and providing emergency services and public infrastructure would solve the problem effectively and improve the overall driving experience.

\section{IoT driven Intelligent Transportation Framework (IoTDITF)}

In this paper, the loT driven Intelligent Transportation Framework (IoTDITF) has been proposed to establish a sustainable transportation system.This paper uses a system dynamics approach for simulating and validating the consequences in emerging cities of various transport development strategies. In transportation-related fields like energy policy for alternative fuel vehicles, transport chain management, road maintenance and construction and transportation land utilization, the system dynamics simulation methodology have been widely utilized. The goal of technology systems in transport should be to adapt to present needs without jeopardizing future generations' capacity to fulfill their own needs. The urbanization of emerging cities will offer jobs that, in effect, attract citizens to mitigate them. In several manufacturing sectors, like industries, logistics, transport, healthcare, loT plays an important role, introducing a revolutionary change to our daily lives. Under loT, various forms of real-time information for public transport systems are accessible and useful to reduce the system's uncertainty and improve the system's ability to adapt efficiently and help to reliably monitor and control the public transport network. Another benefit of loT is that a certain loT-based transportation system has autonomy and the ability to self-coordinate and reduce the amount of data transmission and the computation a burden of the transit control facility. 
The extent of transport operations is driven by two key factors. The general levels of development, revenue and transport supply are concerned in economics. The advanced economy is more likely to produce carriage per unit than anemerging economy. Land use indications to the location of the demand and spatial structure for transport, which indirectly influences travel distances and the methods employed to encourage economic, spatial connections. Activities contain a wide variety of reasons that suggest the utilization of transport infrastructures and other relevant facilities in specific activities that sustain the transport network. All these activities are environmentally friendly. Emission of all kinds (carbon monoxides, nitrogen oxides, etc.) is the first result of transport activities. The environmental pollution rates are determined depending on geological characteristics of the region where pollutants exist (e.g., wind patterns). Since this amount is related to population activity and density rates, a degree of experience to destructivecontaminants may be determined. The consequences of this treatment would be probable. They include very difficult to measure health, environmental and welfare effects of transport emissions exposure. Figure 3 shows the environmental and economic dimensions of transportation.

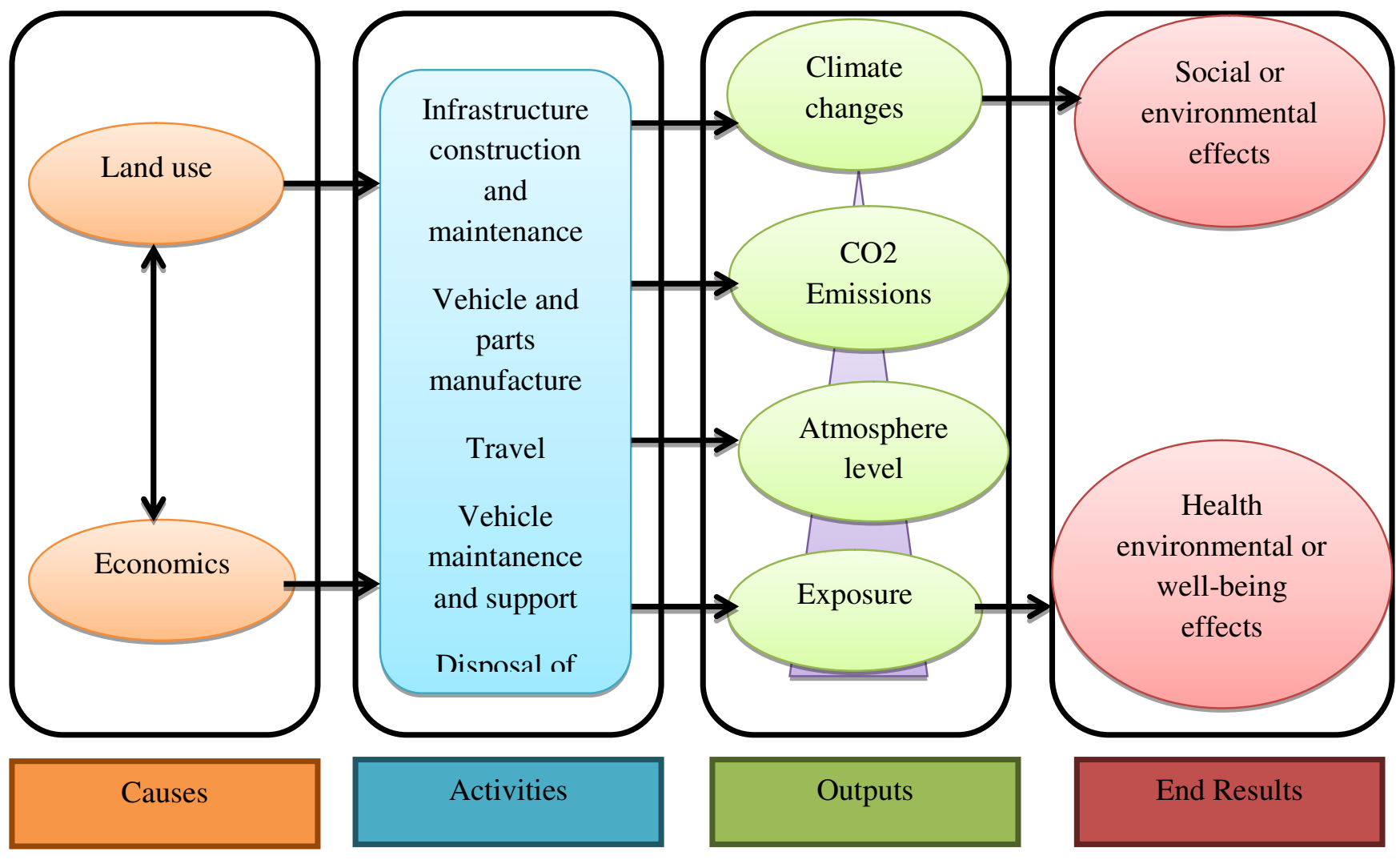


Figure 3: Environmental and economic dimensions of transportation Table 1: Nomenclature

\begin{tabular}{|c|c|}
\hline Variables & Description \\
\hline$\beta, \alpha$ & Retardation variables \\
\hline$\mu$ & Predicted value \\
\hline$\theta$ & Traffic conversion variable \\
\hline$E_{b}$ & Land use area \\
\hline$B_{t}$ & Road capacity of $t$ \\
\hline$B_{l}$ & Road capacity of I \\
\hline$C_{l}^{j i}$ & Flow from $\mathrm{j}$ to I allocated on I \\
\hline$C_{l}$ & Overall flow allocated on I \\
\hline $\mathrm{D}$ & CO2 emissions rate of the average speed \\
\hline$f\left(J_{j i}\right)$ & Impedance from $\mathrm{j}$ to $\mathrm{i}$ \\
\hline$H Q_{l}^{k}$ & $\begin{array}{l}\text { The capacity of smart parking lot } k \text { with an } \\
\text { entrance on road I }\end{array}$ \\
\hline$H E_{l}^{k}$ & $\begin{array}{l}\text { The capacity of affiliated parking lot } s \text { with } \\
\text { an entrance on road I }\end{array}$ \\
\hline$G_{l}$ & Number of routes via the Ith road segment \\
\hline $\mathrm{L}$ & Set of road segments \\
\hline$l$ & $\begin{array}{l}\text { Ith road segment cut by the boundary of } \\
\text { N'on } t\end{array}$ \\
\hline$K_{t}$ & Length of road $t$ \\
\hline$K_{l}$ & Length of road segment I \\
\hline $\mathrm{N}$ & nth feature point of smart parking lots \\
\hline$O_{j i}$ & Flow from $\mathrm{j}$ to $\mathrm{i}$ \\
\hline$O E_{j i}$ & $\begin{array}{l}\text { From } \mathrm{j} \text { to } \mathrm{i} \text { the likelihood of } \forall W E \text { route to } \\
\text { be selected }\end{array}$ \\
\hline$O T_{n}$ & Peak time occupancy ratio of smart \\
\hline
\end{tabular}




\begin{tabular}{|l|l|}
\hline & parking space \\
\hline$O T_{s}$ & $\begin{array}{l}\text { Peak time occupancy rate of affiliated } \\
\text { parking space }\end{array}$ \\
\hline$Q H_{b}$ & The parking generation rate of b \\
\hline$p_{j i}$ & pth trip generated from zone $\mathrm{j}$ to $\mathrm{i}$ \\
\hline $\mathrm{P}$ & pth OD pair \\
\hline $\mathrm{T}$ & Set of roads \\
\hline $\mathrm{P}$ & Total number of OD pairs \\
\hline $\mathrm{T}$ & t-th road defined by intersections \\
\hline & Network emission level \\
\hline$\left.X^{n}, z^{n}\right)$ & Coordinates of nth smart parking location \\
\hline$U_{l}$ & Average traffic speed pass via I \\
\hline$R E_{b}$ & Trip attraction rate of b at peak time \\
\hline$U_{t}$ & Average traffic speed pass via t \\
\hline$R T_{w}$ & Affiliated parking space turnover rate \\
\hline$R T_{n}$ & Smart parking space turnover rate \\
\hline$R H_{j}$ & Trip generation amount of zone $\mathrm{j}$ \\
\hline$R H_{b}$ & $\begin{array}{l}\text { The trip generation rate of land use b at } \\
\text { peak time }\end{array}$ \\
\hline$r_{l}\left(C_{l}\right)$ & Time spend passing via of $U_{l}$ flow \\
\hline$W E_{j i}$ & From $\mathrm{j}$ to $\mathrm{i}$ the number of alternative routes \\
\hline &
\end{tabular}

Table 1 shows the nomenclature used in this study. The sample study with the amount of $\mathrm{N}$ smart parking location is reviewed, involving both previous ones has been created. For simplicity, here, every smart parking location denoted by the central point of their construction region and adds up to from 1 to $n$. The synchronizes of the nth smart parking location are $\left(y^{n}, z^{n}\right)$. Every functional zone proceeds its centroid as the feature item, and the synchronize of $n^{\prime}$ the zone labeled as $\left(y^{n \prime}, z^{n \prime}\right)$. The road network system contains the joint set $M=\{1,2, \ldots, e, . . a \ldots m\}$ and road set $T=\{1,2, \ldots t\}$. 
The following Wardrop principles of traffic activities may be developed as mathematical problems of optimization. Our goal is to analyze the overall transport networks to reach minimal $\mathrm{CO} 2$ emissions. A traffic design then follows the second Wardrop theory, which relates system efficiency optimization, as mentioned below, which will be the optimal resolutionto the curving problem.

$\operatorname{MinX}=\sum_{t} C_{t} \cdot D_{t} \cdot K_{t}$

As shown in equation (1) where $X$ denotes the emission level of the network, $C_{t}$ is the traffic flow on road $\mathrm{t}, D_{t}$ is the average vehicle speed from road $\mathrm{r} \mathrm{CO} 2$ emission ratio and $K_{t}$ is the road length t.

In equation (1) $D_{t}$ is an average traffic speed function $U_{t}$ represented as

$D_{t}=f\left(U_{t}\right)$

Where $U_{t}$ is evaluated as follows

$U_{t}=\frac{K_{t}}{r_{t}\left(C_{r}\right)}$

Where $r_{t}$ is a function of $r_{0}$ as expressed by

$r_{t}=r_{0}\left[1+\beta\left(\frac{C_{t}}{B_{t}}\right)^{\alpha}\right]$

As inferred from the equations (2), (3) and (4) where $r_{0}$ is the road length quotient and the speed of the road design, $r_{t}\left(C_{t}\right)$ is the time consumed by passing via a road at $C_{t}$ flow state. While $r_{0}$ is the road impedancevariable, called the time spend when driving via the road segment with the speed of free-flow. $\beta$ and $\alpha$ are retardation factors evaluated in modeling. Equation (1) can be rewritten as,

$\operatorname{Min} X=\sum_{t} C_{t} \cdot f\left(\frac{K_{t}}{r_{0}\left[\beta\left(\frac{C_{t}}{B_{t}}\right)^{\alpha}\right]}\right) \cdot K_{t}$

As discussed in equation (5) where $f\left\{K_{t} /\left(r_{0}\left[1+\beta\left(C_{t} / B_{t}\right) \wedge \alpha\right]\right)\right\}$ is the original $f(u)$. The curve function is utilized for $f(u)$ evaluation. The $C_{t}$ the flow pattern is the variable in which optimization is needed (5). The main challenge for system emission optimization is thus to validate the network's optimum circulation system. Essentially, all of our subproblems, like smart parking demand forecasts, traffic and trip generations, volume estimation, are focused on our optimized approach to traffic distribution. 


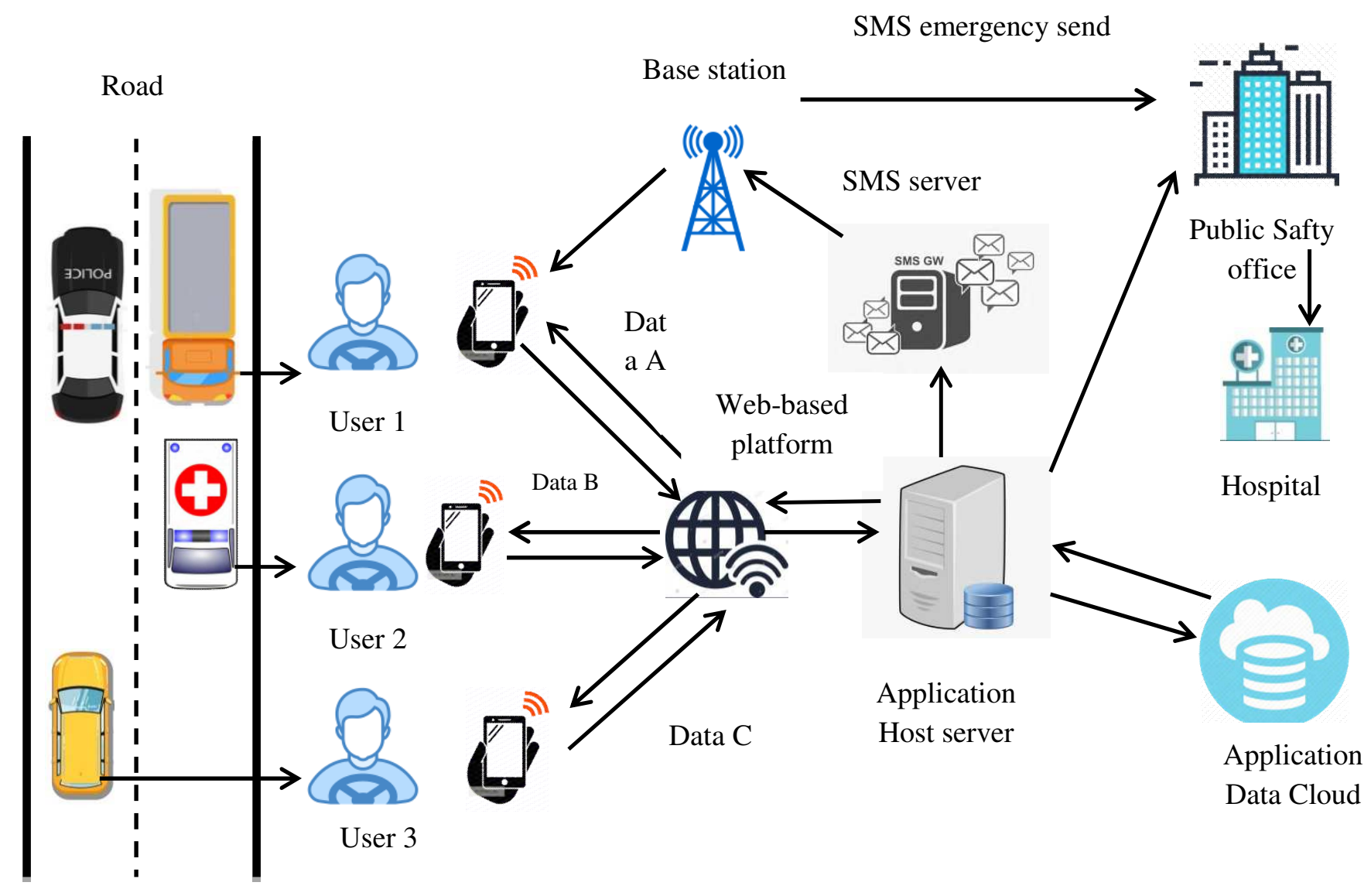

Figure 4: The architecture of the proposed loTDITF system

Figure 4 illustrates the architecture of the proposed IOTDITF method. The road segments are divided by polygon edge with the deliberation of traffic distributions, the segments set is $L=\{1,2, \ldots l\}$. For every road section $l$,

$C_{l}^{\prime}=F C_{l}-H E_{l}^{S} \times O T_{s} \times R T_{s}-H Q_{s} \times V_{q l} \times R_{q l}$

As derived in equation (6) where $C_{l}$ indicated the overall zone to zone traffic flow of road $l, C_{l}^{\prime}$ is the total traffic flow transient via road segments I, F denotes the usage proportionof the vehicle in excess of the total of all traffic tools, $H E_{l}^{S}$ is the volume of the affiliated parking garages on-road $l, H Q_{s}$ is the volume of the smarton-road parking garages $l, R T_{S}$ is the revenuevalue of the affiliated parking region, $O T_{S}$ is the peak-time occupancy rate of affiliated parking region, $R T_{n}$ is the turnover rate of the smart parking space, $O T_{n}$ is the peak-time possession rate of smart parking garages.

In equation (6) the dimensions of the smart parking garage are evaluated as, 
$H Q_{l}^{k}=\sum_{k=1}^{k} \frac{Q C_{j}-H E_{l}^{S} \times R T_{S}}{O T_{n} \times R T_{n}}$

As shown in equation (7) where $\mathrm{k}$ is the number of smart on-road parking garages $\mathrm{I}, Q C_{j}$ indicates the parking demand of zone $\mathrm{j}$,

$Q C_{j}=Q H_{b} \times E_{b}$

As inferred from the equation (8) where $b$ indicates the land-use type, differ from 1-8. $Q H_{b}$ is the parking generation value of $\mathrm{b}$, and $E_{b}$ is the size of $\mathrm{b}$.

In equation (6) $C_{l}$ denotes traffic flow on road $l$ produced by whole tradeoff trips $R_{j i}$. Thus, according to the dynamic zoning approach suggested, the interactive traffic distribution and traffic demand calculation approach based on the gravity model, $R_{j i}=\frac{\varepsilon R H_{j} R E_{i}}{f\left(J_{j i}\right)}$

As shown in equation (9) where $R H_{j}$ denotes trip generation amount of zone $\mathrm{j}, R E_{i}$ denotes trip attraction amount of zone $\mathrm{i}, f\left(J_{j i}\right)$ is the impedance from $\mathrm{j}$ to $\mathrm{i}, \varepsilon$ is the coefficient of the gravity system, which is set to be 0.81 , stated as theless time expended from $j$ to $i$ at speed of free-flow.

In equation (9), $R H_{j}$ and $R E_{i}$ can be evaluated as

$R H_{j}=\sum R H_{b} \times E_{b}$

As discussed in equation (10), where $R H_{b}$ is the land use trip generation rate at peaktime,

$R E_{i}=\sum R E_{b} \times E_{b}$

Where, $R E_{b}$ is the trip attraction rate of $\mathrm{b}$ at peak times.

This dynamic estimation process is employed for the identification of $E_{b}, R H_{j}, R E_{i}, Q C_{j}$, which are according to the iterative zoning process.

Take as an example a trip distribution related to the zoning procedure,

$\left(R_{j i}\right)_{p}=\left[\frac{\varepsilon R H_{j} R E_{i}}{f\left(J_{j i}\right)}\right]_{p}$

Where, $\left(R_{j i}\right)_{p}$ is the pthtrip generated from $\mathrm{j}$ to $\mathrm{i}$,

$C_{l}=\sum_{p=1}^{P}\left\{\left(R_{j i}\right)_{p} s_{n l}\right\}=\sum_{p=1}^{P}\left\{\left[\frac{\varepsilon R H_{j} R E_{i}}{f\left(J_{j i}\right)}\right]_{p} s_{n l}\right\}$ 
As inferred from the equation (13) where $C_{l}$ is the road traffic flow $l$. The road section is labeled from 1 to $l$, specifically relating to the dynamic zoning approach, the road is repeatedly modified. $\mathrm{P}$ is the number of origin-designation pairs. $s_{n l}$ is the relation of the pthorigin-designation pair $\left(R_{j i}\right)_{p}$ assigned road traffic flow $l . \mathrm{p}$ is the number of origindesignation pairs.

Preassuming that from $\mathrm{j}$ to $\mathrm{i}$, there are $\widetilde{W}$ alternative roads in every origin-designation pair. Thus, the behavioral science theory, common samples of the time expended from $j$ to i must followthe standard distribution. The shorter time of a pathperiod, the greater likelihood it could beoccupied. Thus, from $j$ to $i$, the likelihood of $\forall \widetilde{W}$ the path to be selected is calculated as,

$Q_{\widetilde{W}}=\frac{e^{-\frac{\left(R_{\widetilde{W}}-\mu\right)^{2}}{2 \theta^{2}}}}{\sum_{\widetilde{W}} e^{-\frac{\left(R_{W}-\mu\right)^{2}}{2 \theta^{2}}}}$

As shown in equation (14) where $\theta$ is the traffic conversion variable, $\mu$ is the prediction rate as the shortest hoursconsumed from $\mathrm{j}$ to $\mathrm{i}$ for cars, $R_{W}$ is the travel period of every route.

Zone 1

Zone 2
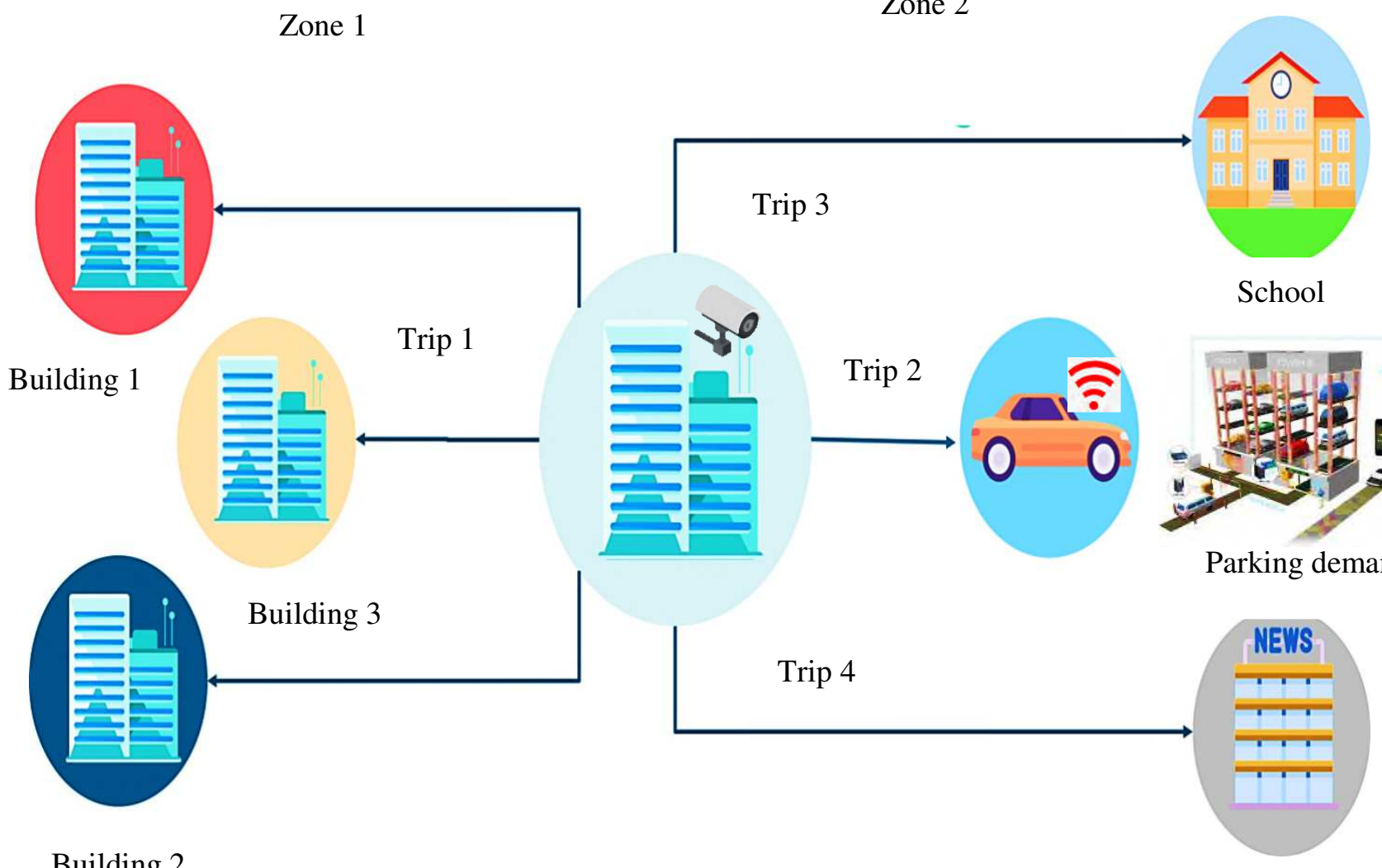

Building 2 


\section{Figure 5: Smart Parking system based on loT}

Figure 5 shows the smart parking system based on loT. Thus, the total likelihood of the pth OD pair assigned on the Ith segment is $s_{n l}$ as expressed by, $s_{n l}=\sum_{w=1}^{G} Q_{\widetilde{W}}$

As discussed in equation (15) where $G$ is the number of paths via the lth road segment, in equation (15) the feasible route $\widetilde{W}$ is identified.

The fitness value is utilized to calculate the resolution outcomes in a generic algorithm. The optimized smart parking location method aims to augment the $\mathrm{CO}_{2}$ emission for the entire traffic system. The fitness value is calculated as

$\operatorname{MinX}=\sum_{l} C_{l} \cdot f\left(\frac{K_{l}}{r_{0}\left[1+\beta\left(\frac{y_{l}}{b_{l}}\right)^{\alpha}\right]}\right) \cdot K_{l}$

Constraints and road constraints flow written assubject to

Subject to. $\left\{\begin{array}{c}\sum f_{l}^{j i}=P_{t w} \\ f_{l}^{j i} \geq 0 \\ C_{l} \geq B_{l}\end{array}\right.$

As inferred from the equation (16) where $f_{l}^{j i}$ denotes the traffic flow from $\mathrm{j}$ to $\mathrm{i}$ on road segment I, $P_{j i}$ denotes the total flow from $\mathrm{j}$ to $\mathrm{i}$.

The paper suggests an optimal method for choosing parking spaces to reduce carbon dioxide pollution from traffic in green urban street networks. A constrained optimization model has been developed through dynamic traffic zone programming to measure the influence of smart alternative parking locations on the emissions of road traffic. This planning system provides an objective solution to the allocation of traffic and the calculation of demand for parking. The method focuses more on the supply-demand of parking, its effect on parking crowding than on quadrilateral or radial zoning. Fitness functions can be a common goal of the shortest distance. The innovative zoning-based parking advice will continue to improve traffic network efficiency with the assistance of smart city technology by delivering real-time traffic data from the roadside ITS sensors. The reliability of parking incorporation and the efficient control of traffic flow may be 
guaranteed for potential intelligent mobility by integrating the efficient zoning and simulation approach into a smart transportation network.

\section{Experimental Results}

\section{(i) Performance Ratio Analysis}

Performance measures permit decision-makers to quickly monitor the effects of a proposed transport plan to monitor trends in the performance of the transport system over time. The proposed loTDITF method achieves the performance measure such as enhance safety, reduce congestion, expand economic opportunity, enhance air quality and increase the value of transportation assets. These models are efficient ways to enhance traffic efficiency by taking into consideration travel speed, time or walking space, etc. If the real-time transit system information is collected through different loT devices, the transit agency may plan the vehicle dynamically to produce improved efficiency. In the case that many planning horizons are taken into account, and real-time information is obtained from the parameters of each planning horizon, the genetic algorithm may be implemented to rapidly find the most optimal solution for each planning horizon. Figure $6(\mathrm{a}, \mathrm{b})$ demonstrates the performance ratio analysis using the suaqested loTDITF method based on tempearture variation.
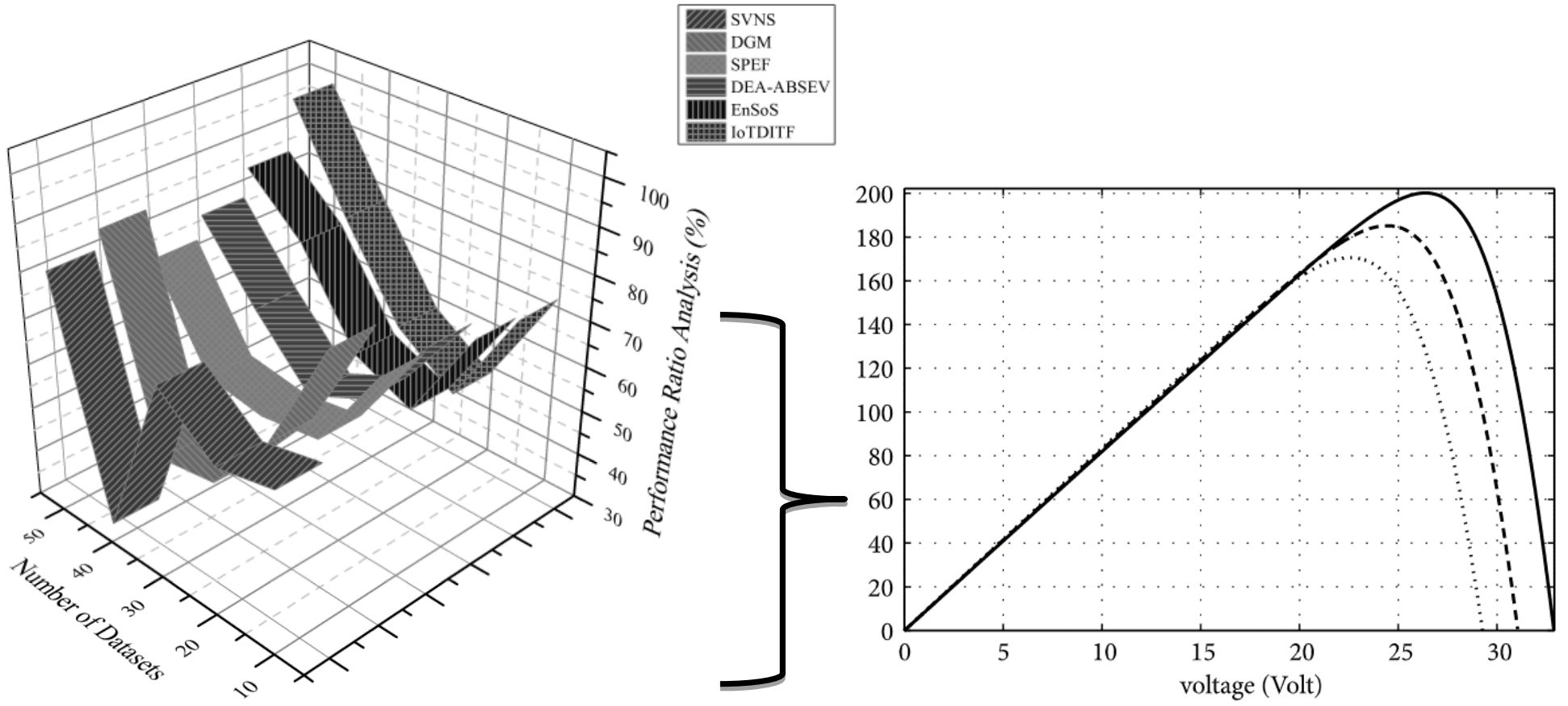

-25 degrees-cent 
(a) Performance analysis

(b) Temperature variation

Figure 6: Performance ratio analysis based on temperature variation

(ii) Reliability Ratio evaluation

Transport and economy are two members of an entity that can not be separated between them. The economic progress and the positive impact on the community economies can be increased through careful planning and appropriate foresight. Transport and economic factors interact easily; the transport sector is an important economic component that affects population growth and wellness. If transport systems are efficient, they offer social and economic opportunities and benefits that have positive multiplier effects, such as improved market access, jobs and additional investment. If carriage systems are not comprehensive in terms of capacity or reliability, economic costs can be reduced or missed. Efficient transport decreases costs, while ineffective transport raises travel costs. Transit often has a social and environmental responsibility that can't be ignored. Economies have two influences on transportation: direct and indirect. Direct effects due to improvements in mobility where transportation will save costs, time and protection and allow larger markets based on the various charges of the vechile. Indirect impacts associated with the economic multiplier effects, as commodity, components or services are reduced and/or their price rises. Figure 7 shows the reliability ratio evaluation using the proposed IoTDITF method.

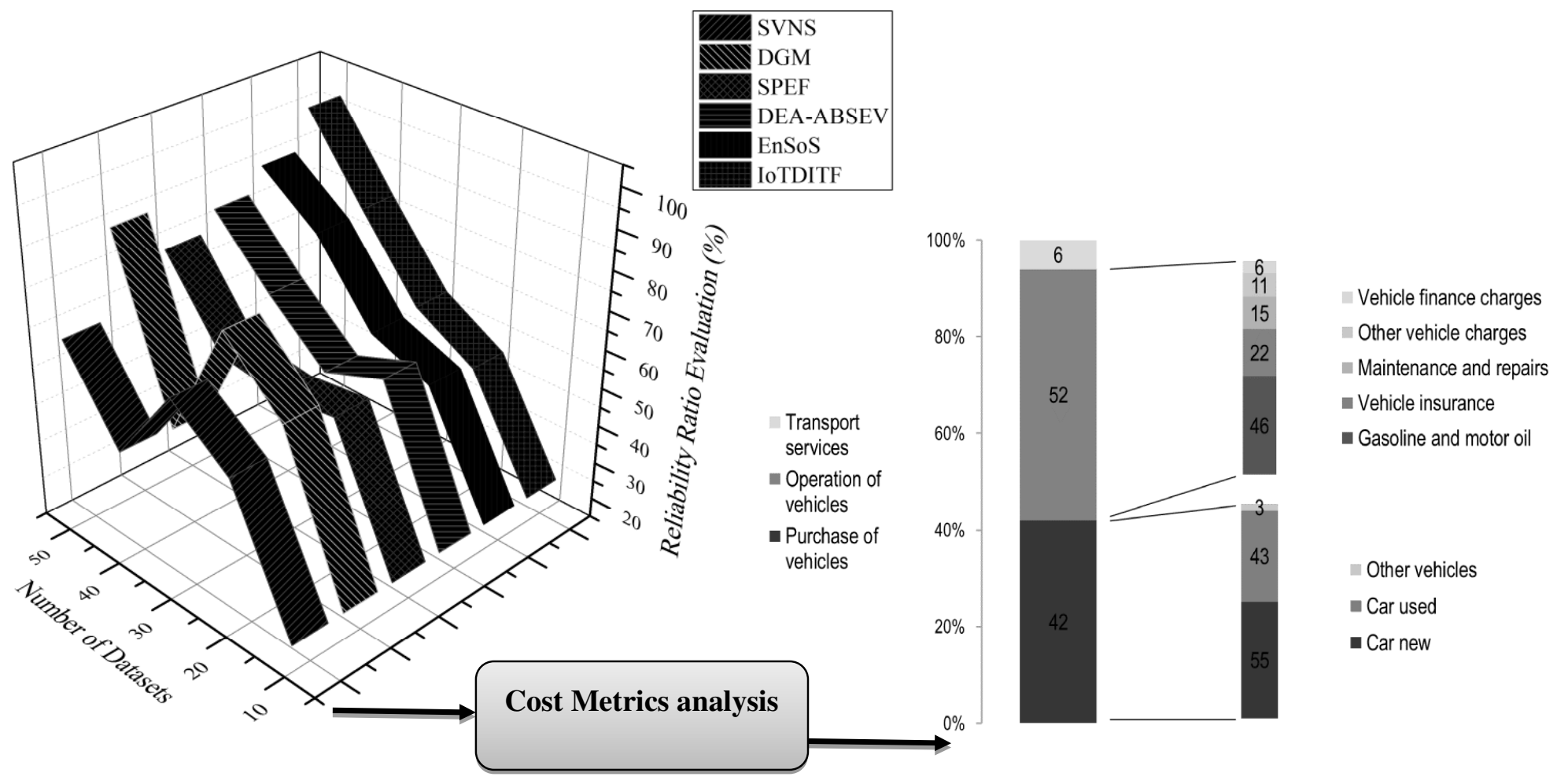




\section{Figure 7: Reliability ratio evaluation}

(iii) Error rate

If the system sensors are deployed more than 0.5 meters away, a vehicle positioning error can arise. The path error might occur if the sensors are not installed properly or because of potholes in the street surface or unknown objects that cause pilots to change direction. They force drivers into the sensor region to turn the steering wheel. Such errors may be minimized in the case of the installation of magnetic sensors where turning is prohibited. There are many factors to the speed estimated error. One of them is the technique for signal processing. In addition, since the speed is calculated using the cross-correlation function, reducing the sample size of signals processed can lead to higher error values (number of data points). Figure 8 shows the error rate of the suggested IoTDITF method. 


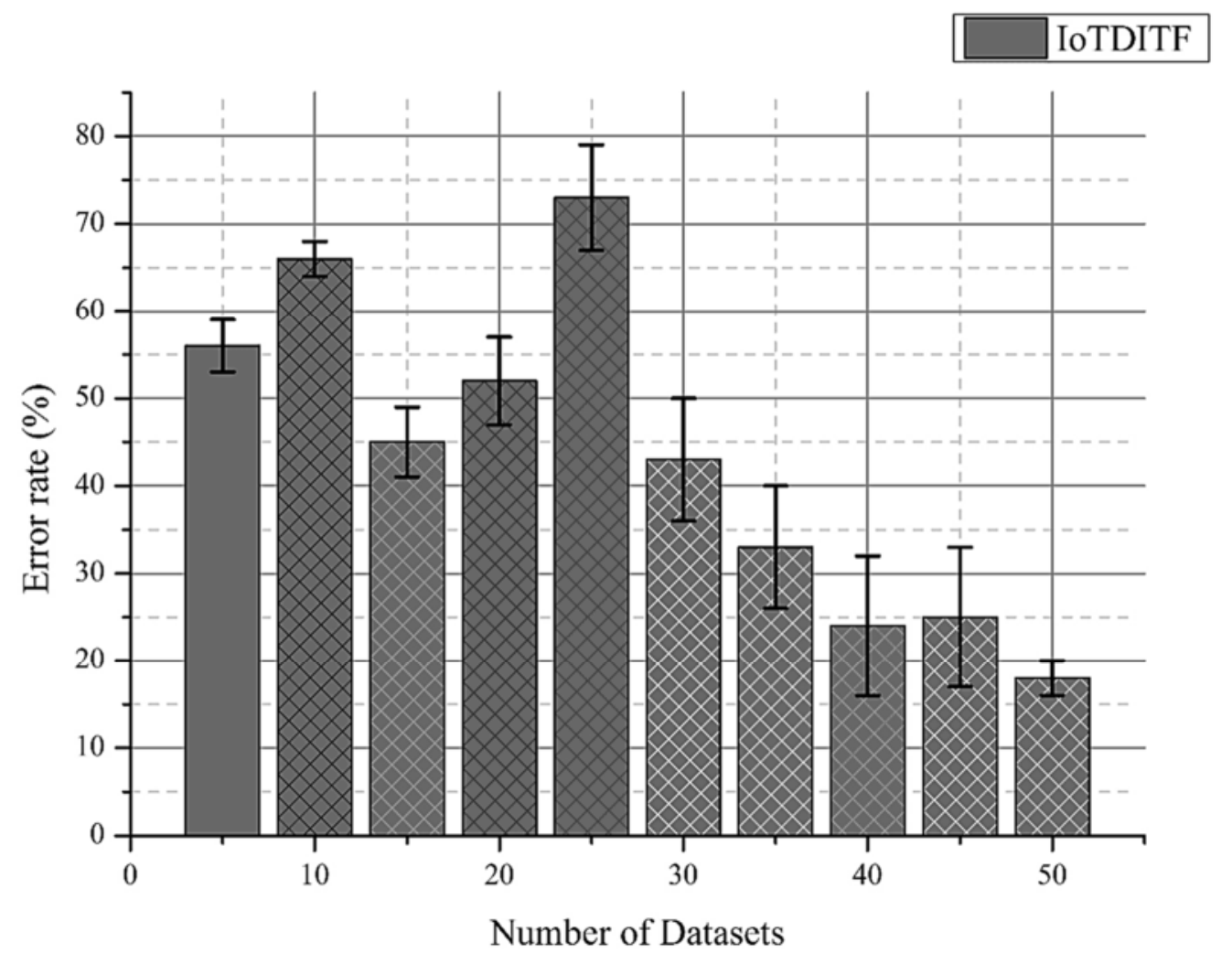

\section{Figure 8: Error rate}

\section{(iv) Computational cost}

ITS allows reducing the time for logistics processing of activities such as numerous transport (loadings and unloading) for the management of large commercial fleets. These systems may help to reduce operating costs, with vehicles spending less on the road, thus improving public health and conservation of the environment. ICTs can allow multi-functional traffic stations for trucks (weighing, traffic counts, axle number, safety and emergency response centers). GPS is used to track trucks under transit (especially in transit countries) from customs and border authorities, to monitor trucks from one border point to another. The proposed loTDITF method reduces the computational cost when compared to other existing approaches. Figure 9 demonstrates the computational cost using the suggested loTDITF method. 


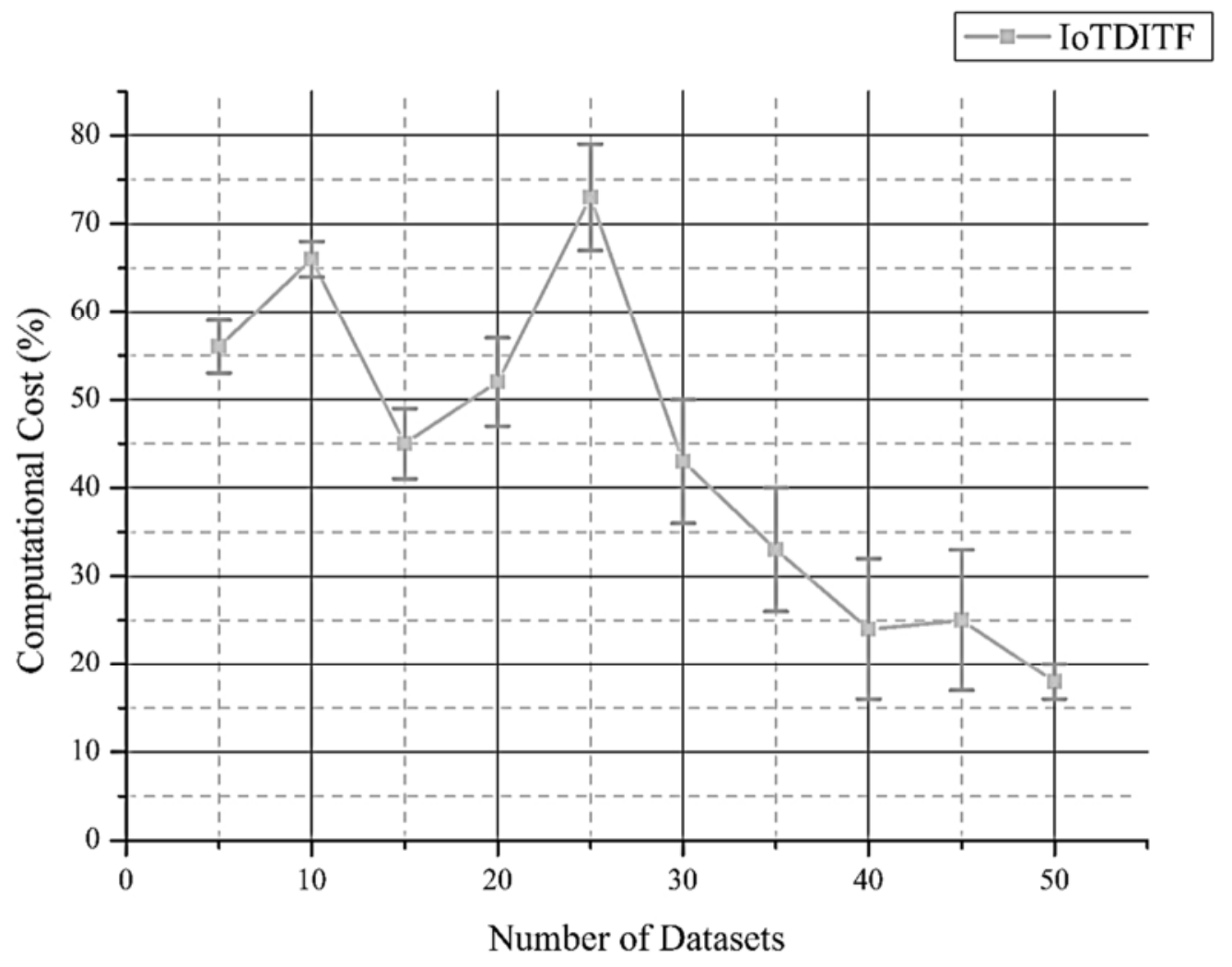

\section{Figure 9: Computational cost}

\section{(v) Scalability ratio}

Sustainable transport should be cost-efficient as regards the economy, leading to the country's economic growth as a whole. In society, it should lead to fewer accidents, fewer commuting times, be safe and provide the traveler and driver with convenience and comfort, resulting in health benefits. The congestion of traffic generates cost and decreases economic growth through the waste of time and energy and slower delivery of goods or services. Sustainable transport will reduce harmful emissions, be environmentally-friendly, utilizing sustainable and inexhaustible energy. The proposed IOTDITF method enhances the scalability ratio when compared to the other existing approaches. Figure 10 demonstrates the scalability ratio using the suggested loTDITF method. 


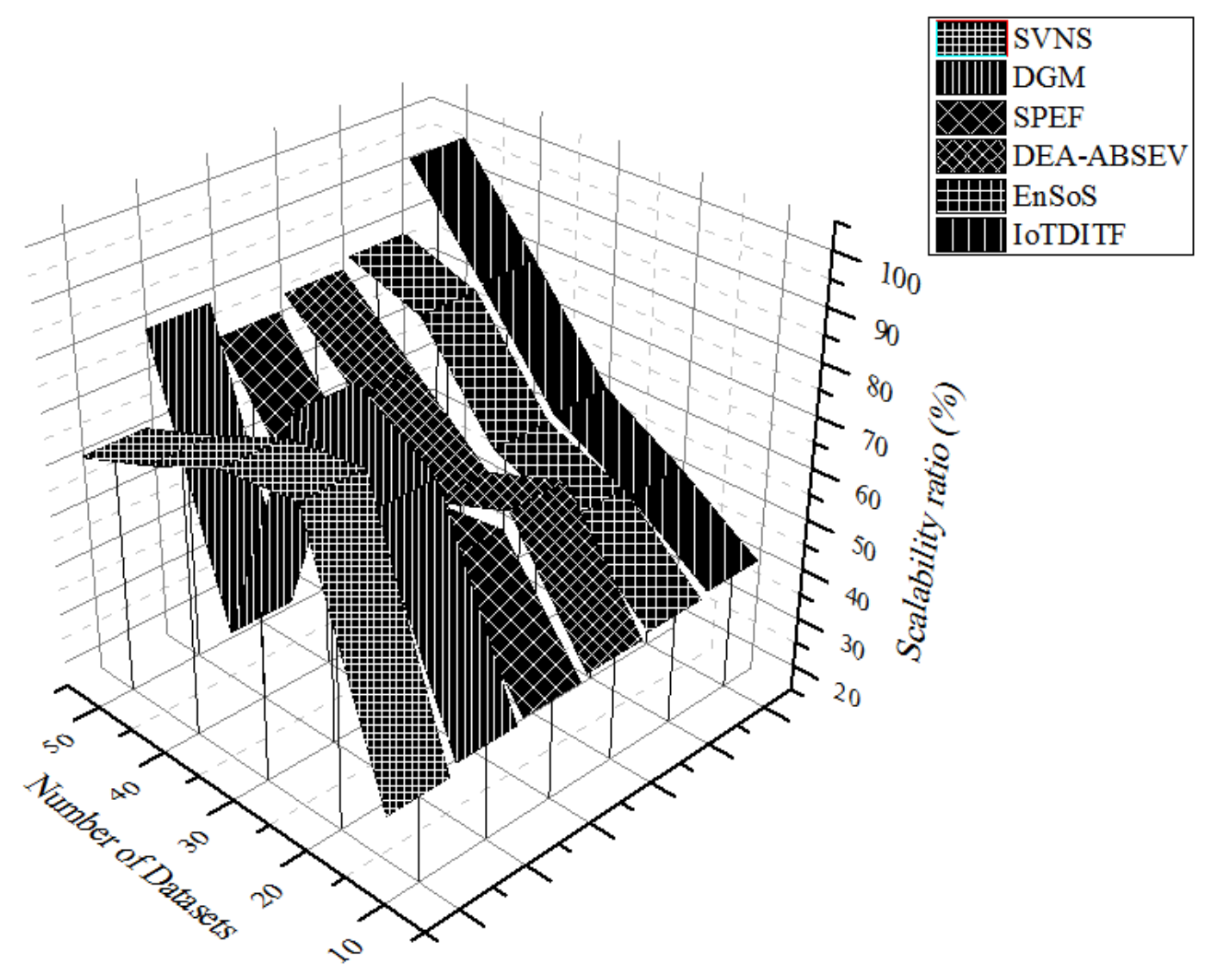

Figure 10: Scalability Ratio

The proposed loT driven Intelligent Transportation Framework (IoTDITF) achieves high performance, enhance the traffic management system efficiency and reduces the $\mathrm{CO} 2$ emission, smart parking system using the internet of things when compared to other existing Single Valued Neutrosophic sets (SVNS) Dynamic Game model (DGM), sustainability performance evaluation framework (SPEF), Data envelopment analysis and accessibility based service effectiveness model (DEA-ABSEV), Environmental and social sustainability framework (EnSoS) methods.

\section{Conclusion and future prespective}

This paper presents the loT driven Intelligent Transportation Framework (IoTDITF) to develop a sustainable transportation system. The traffic model and environmental climate of the smart building in emerging cities need to be scientifically developed, enforced wisely and extensively and adjusted according to local conditions to effectively enhance them. The guiding steps to improve and change the direction and traffic management appropriately. Through promoting low-carbon and efficient mobility, 
intelligent cities can increasingly be developed into a quiet and comfortable traffic network, balanced through soft modes, which is focused on scientific and strict traffic management using the internet of things. The study examines how the end-user can choose the best path. In most cases, the optimum route is beneficial in terms of fuel and total travel time as the shortest route. Through our research managed to create an ideal route and have predicted traffic congestion levels in future using advanced learning habits. The system discusses accident events and how they could affect the traffic flow in a region. The proposed IOTDITF method enhances the reliability and performance ratio when compared to other existing methods.

\section{Ethics Declarations}

\section{Conflict of interest}

The authors declare that they have no conflict of interest.

\section{Ethical approval}

This article does not contain any studies with human participants or animals performed by any of the authors.

\section{Author Statement}

Conception and design of study : Arun M

Acquisition of data : Arun M

Analysis and/or interpretation of data : Arun M

\section{References}

1. Efthymiou, D., Chaniotakis, E., \& Antoniou, C. (2020). Factors affecting the adoption of vehicle sharing systems. In Demand for Emerging Transportation Systems (pp. 189-209). Elsevier.

2. Hotak, M., Turcios, E., Dayrit, D. G., \&Arora, A. (2020). The Road to Sustainable Transportation in Supply Chains: A Stage-Level Approach. In Sustainable Innovation (pp. 59-69). Palgrave Pivot, Cham.

3. Shakeel, P. M., Arunkumar, N., \&Abdulhay, E. (2018). Automated multimodal background detection and shadow removal process using robust principal fuzzy gradient partial equation methods in intelligent transportation systems. International Journal of Heavy Vehicle Systems, 25(3-4), 271-285. 
4. Jraisat, L. (2020). Information Sharing in Sustainable Value Chain Network (SVCN)-The Perspective of Transportation in Cities. In Digital Twin Technologies and Smart Cities (pp. 67-77). Springer, Cham.

5. Aujla, G. S., Jindal, A., \& Kumar, N. (2018). EVaaS: Electric vehicle-as-a-service for energy trading in SDN-enabled smart transportation system. Computer Networks, 143, 247-262.

6. Nahrstedt, K., \& Chang, S. (2016, May). Placement of energy sources for electric transportation in smart cities. In 2016 IEEE International Conference on Smart Computing (SMARTCOMP) (pp. 1-8). IEEE.

7. Henríquez, B. L. P. (2020). Energy sources for sustainable transportation and urban development. In Transportation, Land Use, and Environmental Planning (pp. 281-298). Elsevier.

8. Baskar, S., \&Dhulipala, V. S. (2018). Secure and compact implementation of optimized Montgomery multiplier based elliptic curve cryptography on FPGA with road vehicular traffic collecting protocol for VANET application. International Journal of Heavy Vehicle Systems, 25(3-4), 485-497.

9. Elbert, R., Friedrich, C., Boltze, M., \&Pfohl, H. C. (2020). Urban freight transportation systems: current trends and prospects for the future. In Urban Freight Transportation Systems (pp. 265-276). Elsevier.

10. Appathurai, A., Manogaran, G., \&Chilamkurti, N. (2018). Trusted FPGA-based transport traffic inject, impersonate (I2) attacks beaconing in the Internet of Vehicles. IET Networks, 8(2), 106-115.

11. Baskar, S., Periyanayagi, S., Shakeel, P. M., \&Dhulipala, V. S. (2019). An energy persistent range-dependent regulated transmission communication model for vehicular network applications. Computer Networks, 152, 144-153.

12. Rizk-Allah, R. M., Hassanien, A. E., \&Elhoseny, M. (2018). A multi-objective transportation model under neutrosophic environment. Computers \& Electrical Engineering, 69, 705-719.

13. Çolak, M., Utku, İ. Y., Özmisir, D., Boz, A., Aydoğdu, T., Didiş, M. C., \&Nadar, E. (2020). Sustainable Transportation System Design. In Environmentally-Benign Energy Solutions (pp. 857-876). Springer, Cham. 
14. Sathishkumar, V. E., Cho, Y., \& Park, J. (2020). Seoul Bike Trip Duration Prediction using Data Mining Techniques. IET Intelligent Transport Systems.

15. Tyrinopoulos, Y., \& Antoniou, C. (2020). Review of factors affecting transportation systems adoption and satisfaction. In Demand for Emerging Transportation Systems (pp. 11-36). Elsevier.

16. Daniel, A., Subburathinam, K., Muthu, B., Rajkumar, N., Kadry, S., Mahendran, R. K., \&Pandian, S. (2020). Procuring Cooperative Intelligence in Autonomous Vehicles for Object Detection through Data Fusion Approach. IET Intelligent Transport Systems.

17. Forbord, M., \& Hansen, L. (2020). Enacting sustainable transitions: a case of biogas production and public transport in Trøndelag, Norway. Journal of Cleaner Production, 120156.

18. Chirieleison, C., Montrone, A., \&Scrucca, L. (2020). Event sustainability and sustainable transportation: a positive reciprocal influence. Journal of Sustainable Tourism, 28(2), 240-262.

19. Givoni, M., \& Perl, A. (2020). Rethinking transport infrastructure planning to extend its value over time. Journal of Planning Education and Research, 40(1), 82-91.

20. Givoni, M., \& Perl, A. (2020). Rethinking transport infrastructure planning to extend its value over time. Journal of Planning Education and Research, 40(1), 82-91.

21. Yazdani, M., Pamucar, D., Chatterjee, P., \&Chakraborty, S. (2019). Development of a decision support framework for sustainable freight transport system evaluation using rough numbers. International Journal of Production Research, $1-27$.

22. Wey, W. M. (2019). Constructing urban dynamic transportation planning strategies for improving quality of life and urban sustainability under emerging growth management principles. Sustainable Cities and Society, 44, 275-290.

23. Sultana, S., Salon, D., \&Kuby, M. (2019). Transportation sustainability in the urban context: A comprehensive review. Urban geography, 40(3), 279-308. 
24. Okyere, S., Yang, J. Q., Aning, K. S., \& Zhan, B. (2019). Review of Sustainable Multimodal Freight Transportation System in African Developing Countries: Evidence from Ghana. In International Journal of Engineering Research in Africa (Vol. 41, pp. 155-174). Trans Tech Publications.

25. Mulley, C., \& Nelson, J. D. (2019). Public transportation systems. The Wiley Blackwell Encyclopedia of Urban and Regional Studies, 1-6.

26. Faulin, J., Grasman, S. E., Juan, A. A., \& Hirsch, P. (2019). Sustainable transportation: concepts and current practices. In Sustainable Transportation and Smart Logistics (pp. 3-23). Elsevier.

27. de Mello Bandeira, R. A., Goes, G. V., Gonçalves, D. N. S., Márcio de Almeida, D. A., \& de Oliveira, C. M. (2019). Electric vehicles in the last mile of urban freight transportation: A sustainability assessment of postal deliveries in Rio de Janeiro-Brazil. Transportation Research Part D: Transport and Environment, 67, 491-502.

28. Sałabun, W., Palczewski, K., \&Wątróbski, J. (2019). Multicriteria approach to sustainable transport evaluation under incomplete knowledge: Electric Bikes Case Study. Sustainability, 11(12), 3314.

29. Dyr, T., Misiurski, P., \&Ziółkowska, K. (2019). Costs and benefits of using buses fuelled by natural gas in public transport. Journal of Cleaner Production, 225, 1134-1146.

30.Kaur, H., \&Garg, P. (2019). Urban sustainability assessment tools: A review. Journal of cleaner production, 210, 146-158.

31.Smith, P. (2019). Exploring public transport sustainability with neutrosophic logic. Transportation Planning and Technology, 42(3), 257-273.

32. Wang, Q., \& Sun, H. (2019). Traffic structure optimization in historic districts based on green transportation and sustainable development concept. Advances in Civil Engineering, 2019.

33. Pathak, D. K., Thakur, L. S., \&Rahman, S. (2019). Performance evaluation framework for sustainable freight transportation systems. International Journal of Production Research, 57(19), 6202-6222. 
34.Chen, Y., Bouferguene, A., Shen, Y., \& Al-Hussein, M. (2019). Assessing accessibility-based service effectiveness (ABSEV) and social equity for urban bus transit: A sustainability perspective. Sustainable Cities and Society, 44, 499510.

35. Fu, L., Sun, Z., Zha, L., Liu, F., He, L., Sun, X., \& Jing, X. (2020). Environmental awareness and pro-environmental behavior within china's road freight transportation industry: Moderating role of perceived policy effectiveness. Journal of Cleaner Production, 252, 119796. 